An Exploration of Personality and Speed Limit Compliance

\author{
Deborah Griffin* \\ Department of Marketing \\ Griffith Business School, Griffith University \\ Queensland 4222, AUSTRALIA \\ deborah.griffin@griffith.edu.au \\ Phone 001161 (0)7 55529104
}

and

Aron O’Cass

Newcastle Business School

University House, University of Newcastle

Callaghan NSW 2308, AUSTRALIA

aron.ocass@newcastle.edu.au;

Phone 001161 (0)2 4921 7729;

* author for correspondence 


\begin{abstract}
Research suggests that non-compliance with speed limits is high (Poulter \& McKenna, 2007). One factor that may provide some explanation for individuals' speeding behavior is the driver's personality. To examine social issue behavior in relation to speeding, this study examined specific personality characteristics in the context of speed limit compliance behavior. To test the hypotheses data were gathered via an online survey. The results indicate personality, along with social issue involvement influenced speed limit compliance behavior.
\end{abstract}

Keywords: social marketing, personality, speed limit compliance 


\section{An Exploration of Personality and Speed Limit Compliance}

Each day individuals make behavioral choices that have ramifications for themselves as well as society. One such behavior is speeding in motor cars, which in the United States is a major contributing factor in road crashes (National Highway Traffic Safety Administration [NHTSA], 2009). Speeding can be 'driving too fast for conditions' or 'driving in excess of the posted speed limit' and, although both speeding behaviors are a contributing factor in more than $99 \%$ of fatal speeding related fatal crashes, driving above the posted speed limit is responsible for more than half that number (NHTSA, 2009). In addition, it is estimated that the economic cost of speeding is approximately $\$ 40$ billion a year (NHTSA, 2009). Therefore, research addressing 'speed limit compliance', defined as traveling above the posted speed limit (Poulter \& McKenna, 2007) is an important topic.

Social marketing as a behavior change strategy has been utilized as a means to address a range of social issues, especially speeding. As such, many societies have responded with programs designed to try to reduce speeding and minimize its impact (Australian Transport Council; Department for Transport [UK]. Social marketing as an approach to bring about positive social change, is based on the assertion that an individual takes an action (Andreasen, 1995; 2006). This point highlights the view that, regardless of the influence of social marketing, ultimately the behavioral change is within the realm of the individual.

Therefore, the objective of this research is to examine specific intrapersonal factors that may have the potential to influence individuals’ speed limit compliance behavior. To examine this contention, this research focuses on the individual characteristics of risk aversion, locus of control, consideration of future consequences, susceptibility to normative influence and social responsibility along with social issue involvement as drivers of speed limit compliance behavior. 


\section{Theoretical Background}

The primary aim of social marketing is to influence behavior (Andreasen 1995; 2006).

Therefore, within the context of speed limit compliance, pro-social behavior occurs when an individual adopts the sought after behavior (Rothschild, 1999). However, the challenge for social marketers is that the behavior change is generally voluntary (Kotler \& Lee, 2008) and, therefore, ultimately, it is up to the individual whether they engage (or not) in the desired behavior being marketed or, comply with the law regarding speeding.

Individuals arrive at a situation with an a priori set of characteristics which have the capacity to influence their responses to it. For instance, the factors that lead individuals to comply with the speed limit and, therefore, demonstrate the pro-social behavior promoted in the community may be, in part, explained by their personality characteristics. However, there is a tendency for traffic safety campaigns to ignore the role of personality characteristics (Ulleberg \& Rundmo, 2003). This is surprising given that personality traits have been found to be a factor in individuals’ predisposition to engage in risky driving behaviors (Schwebel, Severson, Ball \& Rizzo, 2006; Ulleberg \& Rundmo, (2003).

Personality traits can be defined as dispositional characteristics in which one person differs from another in an relatively enduring and consistent manner (Blackwell, Miniard \& Engel, 2006). However, in order to gain an insight into the function of personality characteristics in relation to speed limit compliance behavior, the view adopted here takes a more encompassing approach to the influence of personality traits. For example, this research takes a multi-trait view by utilizing four generalized traits that (individually) have been found to predict a range of behaviors. Therefore, it is proposed that an aggregation of four traits (risk aversion, locus of control, consideration of future consequences and susceptibility to normative influence) can be 
viewed as a multi-dimensional construct expressed as a representation of personality, focusing on individuals' propensity to comply with the speed limit, which may provide a richer explanation of speeding behavior. Although these traits are not exhaustive, they are a starting point in understanding important elements that relate to speed compliance behavior.

Many social issues have associated risk taking behaviors implying that there are individuals who speed in motor vehicles by not complying with designated speed limits. Why some people engage in such risky behaviors, and others do not, may be explained by the view that risk taking can be considered a generalized personality trait (Dählback 1990). Individuals are inclined, in varying degrees, to take or avoid risks across situations (Cooper, Wood, Orcutt \& Albino, 2003; Jackson, Hournay \& Vidmar, 1972; Sitkin \& Weingart 1995) and, moreover, an individual’s behavior, is determined by the level of risk they perceive is associated with that behavior. These circumstances may translate into risk taking individuals perceiving less risk associated with speeding than those individuals who are risk averse. Thus, a social marketing campaign that highlights the risks associated with driving above the speed limit, may have little affect on individuals who are less risk averse. If this is so, it may logically follow that a trait that characterizes an individual as being more or less risk averse, would impact on an individual's propensity to comply with the speed limit (see Figure 1).

Apart from risk aversion, the control individuals perceive they have over their driving behaviors may be a factor in how they respond to speeding compliance and social marketing campaigns associated with speeding given the view that perceived control is related to a person's perception of risk and their judgement of risk (Benthin, Slovic \& Severson 1993; Smith \& Rosenthal, 1995). Perceived control may be viewed in the context of locus of control which focuses on individuals perceiving themselves as having some causal role in determining the 
outcome of specific events. Research into locus of control distinguishes between individuals with an internal locus of control who perceive behavioral outcomes to be within their control and individuals with an external locus of control who perceive outcomes are beyond their control and a function of fate, luck or powerful others (O’Cass 2004; Rotter 1966).

An internal locus of control has been linked to a range of positive behavioral outcomes within a range of specific domains including, the environmental domain (Hines, Hungerford \& Tomera, 1986; Schwepker \& Cornwell 1991) and health domain (Strickland 1978; Wallston \& Wallston 1981). In these domains, a greater perception of control equates with engaging in behaviors promoted in the community. However, a greater perception of control may also be a factor for engaging in behaviors not promoted in the community, for example, not complying with the speed limit as it seems there is a tendency for some individuals to feel more in control of their driving than they actually are (Stead, Tagg, MacKintosh \& Eadie, 2005). This situation may arise because drivers who perceive themselves as having more control (over their driving) are comfortable with a higher level of risk (Horswill \& McKenna, 1999) and, therefore, may be more likely to not comply with the speed limit (see Figure 1).

Further, an individual's time orientation may also be a factor for not complying with the speed limit given the premise that an individual's perspective on time (e.g., past, present and future) is related to risky driving behavior (e.g., driving fast) (Zimbardo, Keough \& Boyd, 1997). Time orientation may be viewed in terms of a trait termed consideration of future consequences (CFC), which is seen as a measure of the extent to which individuals consider the future in choosing their current behaviors (Strathman, Gleicher, Boninger \& Edwards, 1994). Within the context of social issues, research indicates that individuals high in CFC are more likely to practice pro-social behaviors (e.g., environmental, health, safe sex) (Ebreo \& Vining 2001; 
Lindsay \& Strathman 1997; Strathman et al., 1994; Rothspan \& Read, 1996) suggesting that these individuals are willing to forgo "immediate pleasure or convenience to achieve more desirable future states (Strathman et al., 1994, p. 742). Therefore, it would seem that high CFC individuals may have a greater awareness of the future implications of their current behavior, (or are less focused on the immediate) than those individuals low in CFC which should be a contributing factor to propensity to comply with the speed limit (see Figure 1).

Interpersonal influence has also been widely recognized as a determinant of behavior (Bearden, Netemeyer \& Teel, 1989; Lascu, Bearden \& Rose, 1995). Within the marketing literature, interpersonal influence has been examined with the context of consumer susceptibility to interpersonal influence (Bearden et al., 1989). However, more recently, interpersonal influence has been examined across a broad range of social issue behaviors such as smoking, binge drinking, illicit drug and alcohol consumption and adolescent sexual behavior (e.g., Griffin \& O’Cass 2004; Kropp, Lavack, Silvera \& Gabler, 2004; Moore Raymond, Mittelstaedt \& Tanner, 2002; Rose, Bearden \& Teel, 1992).

According to Bearden et al. (1989), interpersonal influence is manifested via normative or informational influence. However, the dimension of interpersonal influence that is manifested via normative influence may be of particular interest with regard to social issue behaviors, because it focuses on how concern for others' opinions, compliance to others' expectations and tendencies to emulate others can influence one's behavior (Bearden et al., 1989). Relating this situation to social issues, it may be that those social issue behaviors that are more observable are also more susceptible to normative influence. For example, Kropp et al. (2004) found that susceptibility to normative influence was a factor for college students' alcohol consumption in that those students more susceptible may increase their frequency and amount of drinking. Of 
interest is that this negative circumstance occurs despite the accepted view that there are risks associated with excess alcohol consumption. Therefore, it is argued here that, for those individuals more susceptible to normative influence, their driving behaviors may also be shaped, to some extent, by such influence resulting in non-compliance with the speed limit. This situation may occur because in some circumstances being susceptible to the influence of peers or significant others (who may speed), carries more sway than community norms (i.e., complying with the speed limit). Thus, along with the aforementioned traits, lower susceptibility to normative influence contributes to the multi-dimensional construct, propensity to comply with the speed limit which is presented in Figure 1.

According to Buss (1989), each time one adds a trait one moves closer to understanding persons as combinations of traits. Therefore, grouping the specific traits outlined here provides greater clarification of the personality of the individual and their propensity to comply (or not) with the speed limit. To this end we label our configuration of traits as a higher order construct 'propensity to comply with the speed limit'. This contention is premised on the argument that individuals’ who are risk averse (i.e., high in risk aversion), externally oriented (i.e., low locus of control), future focused (i.e., high consideration of future consequences) and not conforming to the expectations of others (i.e., low in normative influence), will be more likely to respond to positively to the speeding social issue, and therefore, act accordingly and comply with speed limits. Thus,

H1: The higher order construct of propensity to comply with the speed limit has a significant positive effect on speed limit compliance behavior.

The nature of social issues is that they are matters of concern pertaining to society as a whole. In addition, individual behaviors that relate to social issues have consequences (positive 
or negative) that extend beyond the individual to society. For example, given the negative societal consequences related to speeding, it would seem that individuals who engage in the positive behavior (by complying with the speed limit) are behaving in a manner that enhances the well-being of other people and the wider society and, as such, exhibit a notion of social responsibility (Berkowitz \& Lutterman, 1968). According to Green and Webb (1997), social responsibility can be liked to a social motivation based on internalized standards of conduct without expectation of reciprocation.

The importance and strength of this characteristic varies for individuals, however, it could be assumed that social responsibility motivations would be reflected in pro-social behaviors (Anderson \& Cunningham 1972; Berkowitz \& Lutterman 1968; Tucker, Dolich \& Wilson, 1981). Therefore, in terms of the speeding social issue, it could be inferred that individuals with a propensity to comply with the speed limit would also be more socially responsible. As such, social responsibility is included in the model as shown in Figure 1. Thus,

H2: $\quad$ The higher order construct propensity to comply with the speed limit has a significant positive effect on social responsibility.

The discussion, thus far, has been on individual characteristics and their influence on speed limit compliance behavior, rather than the social issue that frames the behavior. However, given that the topic of 'speeding' is a social issue of concern for society, some discussion is also warranted on role the that this issue may have in a person's life. This point may be viewed in the context of social issue involvement, in that if a social issue matters to, or is of importance in a person’s life - they are involved (O’Cass, 2000). Involvement has been shown to have a significant influence on a wide range of consumer behaviors (Mitchell, 1979; Gainer, 1993; O’Cass, 2000); however, there has been limited interest in the role of involvement in relation to 
social issues and associated behavior (Griffin \& O’Cass, 2004). Nevertheless, many of the behavioral choices social marketers attempt to influence entail high involvement decisions (Andreasen, 1995).

Drawing on Mittal’s (1995) description of involvement as a person’s perceived importance of the object, it is suggested here that it may not matter what represents the 'object', (that is, product or social issue ) as long as it is deemed to be of concern, important or matters to the individual - it is involving. Importantly though, involvement here is viewed in the context of the pro or positive involvement in the (speeding) social issue (Griffin \& O’Cass, 2004). For that reason, individuals who engage in the behavior promoted in the community by not speeding (and complying with the speed limit) would be deemed to have higher issue involvement than individuals who do speed. Therefore, it would seem that one's propensity to comply with the speed limit would influence one’s involvement in the speeding social issue and, as such, involvement is included in the model as shown in Figure 1. Thus,

H3: The higher order construct propensity to comply with the speed limit has a significant positive effect on involvement in the speeding social issue.

In characterizing the socially responsible individual, Berkowitz and Lutterman (1968) allude to the notion that those individuals high in this orientation tend to have a greater degree of involvement with their community (e.g., volunteering) and institutions within society (e.g., politics). Extending this theme, Anderson and Cunningham (1972) also found socially responsible consumers to be more involved in community activities, whilst Webster (1975) developed his social involvement model to provide some explanation for socially responsible consumers. Thus, given the premise that the speeding social issue is a matter of concern or importance within society it may also follow that a socially responsible person should be more 
issue involved (as represented in Figure 1) in regard to speeding than a person who is not socially responsible. Thus,

H4: Social responsibility has a significant positive effect on involvement in the speeding social issue.

Research has also shown that involvement has an influence on a wide range of behaviors, including voting (O’Cass, 2004), arts attendance (Gainer, 1993; Hume \& Mort, 2008) and recycling (Stanley, Lasonde \& Weiss, 1996). On this latter point, Stanley et al. (1996) found that involvement with environmental issues was significantly related to associated environmental behaviors (for example, recycling and purchasing green products). This would seem to infer that individuals with higher issue involvement are more likely to appraise the merits of undertaking the related social issue behaviors, than those less involved individuals. This implies that involvement may be seen to have a direct influence on the behavior, of those involved with social issues (as shown in Figure 1) (Griffin \& O’Cass, 2004; Stanley et al., 1996). Thus,

H5: Involvement in the speeding social issue has a significant positive effect on speed limit compliance behavior.

\section{--- Insert Figure 1 in here ---}

\section{Methodology}

The study was based on the development and administration of a survey to collect the data to test the hypotheses. The administration of the survey was via a web-based self-administered method. The data collection involved the researcher sending an email to respondents via the email system of an Australian university. The email included information on the purpose of the study, as well 
as a link to a unique Web site location where the 'Speeding - a Social Issue’ survey could be accessed. The data collection for the study ceased four weeks after the launch of the study and any data collected after this date was not used in subsequent analysis.

\section{Measurement Development.}

Social responsibility was measured by four items sourced and adapted from Berkowitz and Lutterman’s (1968) eight-item Social Responsibility Scale (SRS). Locus of control was measured by 11 items sourced from an adaptation of the shortened form of the James (1957) internal external control scale (O’Cass, 2004). Consideration of future consequences (CFC) was measured by four items sourced and adapted from Strathman et al. (1994) 12 item CFC measure. Susceptibility to normative influence was measured by eight items sourced from the Bearden et al. (1989) consumer susceptibility to interpersonal influence (CSII) scale. Risk aversion was measured by four items sourced and adapted from Dählback's (1990) 11 item measure of declared risk taking. Social issue involvement was measured by five items sourced and adapted from Mittal's (1995) five item involvement measure. The instructions for the involvement scale requested respondents to answer the five statements in relation to the 'Speeding social issue'. For a complete list of the items refer to Table 1.

The scale response and format adopted for the study was a seven-point Likert scale anchored at 1 (strongly disagree) and 7 (strongly agree). Speed limit compliance behavior was measured by a categorical variable that required respondents to choose the response that described their behavior most of the time (I $\underline{\text { do }}$ drive over the speed limit; I do not drive over the speed limit). 


\section{Results}

The administration procedure yielded 558 completed surveys. The preliminary analysis indicated that respondent ages ranged from 18 to 67 and females formed the majority of respondents $66 \%$. In describing their behavior, most of the time, $40 \%$ stated they $\underline{\text { do }}$ travel over the speed limit. The outer model (i.e. measurement model) was examined using PLS. Table 1 provides the loading, reliability and average variance explained for all constructs. The results indicate all measures performed well psychometrically.

\section{--- Insert Table 1 in here ---}

The relationships depicted in the hypotheses were tested using Partial Least Squares (PLS) a multivariate, variance based technique used for estimating path models involving latent constructs indirectly observed by multiple indicators. PLS path modeling allows for the conceptualization of a second-order measurement model through the repeated use of manifest indicators (e.g., Chin, Marcolin, \& Newstead, 2003; Tenenhaus, Vinzi, Chatelin \& Lauro, 2005; Wetzels, Odekerken-Schröder, \& van Oppen, 2009). To approximate the second-order measurement model for propensity to comply with the speed limit, we adopted this repeated indicator approach, which is widely used in the extant literature (e.g., Reinartz, Krafft, \& Hoyer, 2004; Ulaga \& Eggert, 2006). PLS focuses on the explanation of variance using ordinal least square, this technique is better suited for the investigation of relationships in a predictive rather than a confirmatory fashion (Fornell \& Bookstein 1982). In this study the primary concern is maximizing the prediction of dependent endogenous construct. 
Additionally, PLS is generally identified as being very suitable for modeling latent constructs as either formative or reflective (Fornell \& Bookstein 1982; Fornell \& Cha 1994) and represents a well-substantiated method for estimating complex cause-effect relationship models (Gudergan, Ringle, Wende \& Will, 2008). Finally, as PLS allows the examination of measures and theory simultaneously (e.g., Fornell \& Bookstein 1982), it was used for examining the measurement properties (outer-measurement model) and hypotheses (inner-structural model) which provides specification through two sets of linear equations namely outer-measurement model and inner-structural model (Fornell \& Cha 1994).

Two sets of linear relations specify the model: the outer model relationships between the latent and the manifest variables; and the inner model where the hypothesized relationships between the latent variables are specified and whose interpretation is as for standardized regression coefficients (weights). The focus here is on the inner results as they relate directly to H1 to H5. Evaluation of the relationships was via statistical results that attempt to explain the data, congruence with the hypotheses and precision. An examination of hypotheses results was undertaken via $\mathrm{r}^{2}$, average variance accounted for (AVA), average variance extracted (AVE), and regression weights and bootstrap critical ratios (t-values) and path variance.

Given the analysis and arguments presented, our attempt is to advance the operationalization of global personality perspectives by specifying the construct 'propensity to comply with the speed limit' as a second-order factor having first-order factors as formative indicators and the first-order factors themselves having reflective indicators (Jarvis, Mackenzie \& Podsakoff, 2003). Table 2 provides the weight relations of the formative components of propensity to comply with the speed limit. Given that no minimum threshold for indicator weights has been established, the statistical significance of the weights can be used to the 
determine the differential impact of the indicators in forming the latent variable (Ravichandran \& Rai, 2000). As indicated by the results in Table 2, all except the indicator weight for locus of control are statistically significant, however, given the exploratory nature of this study the measurement model was not refined (see also Ravichandran \& Rai, 2000).

In Table 3, the AVA for the endogenous variables is of an acceptable magnitude in the inner model at .12. As advocated by Falk and Miller (1992) the significance of the individual paths was examined by calculating the product of the path coefficient and the correlation coefficient. This produces an index of the variance in an endogenous variable explained by that particular path, where $1.5 \%(.015)$ of the variance is recommended as the cut off point for acceptable path variance magnitudes. As shown in Table 3, all paths except H2 exceed this criterion. Defined as the ratio between estimate and standard errors, critical values greater than 1.96 are statistically significant at 95\%. As such, with the exception of H2, the bootstrap critical ratios are of magnitudes above the acceptable benchmarks. Overall, the results used to evaluate the hypotheses indicate that all except $\mathrm{H} 2$ are supported.

\section{--- Insert Table 2 in here ---}

\section{Discussion}

The aim of this study was twofold. Firstly, the aim was to estimate if personality via an aggregation of four traits (i.e., risk aversion, locus of control, consideration of future consequences and susceptibility to normative influence) could provide an explanation of an individuals propensity to comply with the speed limit. Secondly, the aim was to estimate the importance of these personality traits, along with social responsibility and social issue 
involvement, in relation to self-reported speed limit compliance behavior. The results demonstrate empirical support for the approach taken here that, the aggregation of traits (i.e., risk aversion, locus of control, consideration of future consequences and susceptibility to normative influence) provide some explanation of a configuration of personality represented as propensity to comply with the speed limit. Moreover, taking the lead from these findings, personality factors provide a basis to understand individuals' speed limit compliance behavior. This explanation is also enhanced through including social responsibility and social issue involvement. This means that those individuals with greater propensity to comply with the speed limit also have a greater likelihood of not speeding and, therefore, engaging in the pro-social behavior promoted in the community. In addition, they will tend to be more socially responsible and more issue involved.

In terms of the personality construct, 'propensity to comply with the speed limit', because it is conceptualized as an explanatory combination of the individual traits, there are differences in the relative importance and, therefore, the impact of each trait on the underlying construct. For example, perceived control has the least impact, followed by susceptibility to normative influence, risk aversion with consideration of future consequences having the most impact. In addition, the findings indicate that (in contrast to the other two traits) the relationships between susceptibility to normative influence, perceived control and underlying construct are negative. Thus, as expected, a lesser concern for conforming to the expectations of others (Bearden et al., 1989) translates into a greater propensity to comply with the speed limit.

This situation may occur because, based on McGuire’s (1968) notion of influenceability, these individuals are less susceptible to social influence and, as such, less likely to change an opinion or judgment because of social pressure. In addition, it may be the nature of the social issue and related behavior that is a pertinent here. For example, interpersonal influence was 
found to be a factor for risky behaviors such as drugs and alcohol consumption (Rose et al., 1992). Speeding is also a risky behavior, therefore, perhaps individuals who are less susceptible are also more likely to account for this risk. As demonstrated by the finding here, this may translate into a greater propensity to comply with the speed limit and, therefore, not speed.

Lastly, although the indicator weight for locus of control was not statistically significant, the negative relationship shown by the results does support the view that speeding behavior may be a function of individuals perceiving themselves more in control of their driving than they actually are (Stead et al., 2005). Therefore, in the context of driving behavior that sense of control may have a negative impact resulting in a greater propensity not to comply with the speed limit.

The hypothesized relationship between propensity to comply with the speed limit and social responsibility was not supported. Nevertheless, social responsibility did have a positive effect on social issue involvement. As mentioned previously, an orientation towards social responsibility means one is more likely to behave in a manner that enhances the well-being of others and the wider society (Berkowitz \& Lutterman, 1968). This being the case, and as shown by the results, one would expect being predisposed towards social responsibility means one is more likely to find the speeding social issue involving because it is an issue which is a matter of concern for society.

According to Laurent and Kapferer (1985), understanding the sources of an individual's involvement provides a dynamic picture of their actual situation. This may be so, because as shown by the findings here, the characteristics embedded in personality via an individual's propensity to comply with the speed limit is a source of their involvement in the speeding social 
issue. In contrast, a lesser propensity to comply with the speed limit may depict why some individuals exhibit indifference, lack of care, or unimportance regarding the focal social issue.

The positive impact of social issue involvement on speed compliance behavior highlights the view that when individuals find issues involving or relevant in their lives they are more likely to engage in the associated positive or pro-social behaviors (Griffin \& O’Cass, 2004; Stanley et al., 1996). As previously mentioned, the nature of social issues is that they are matters of concern to society, therefore, they should be involving. However, as demonstrated by the findings here, this is not always the case because only some people place importance on the speeding social issue and, those that do not, will be more likely not to comply with the speed limit. Therefore, to sum up the finding of this study, an individual's personality and issue involvement can influence their driving behavior.

\section{Limitations and Implications}

There are a number of limitations that warrant a mention. The findings may not generalize beyond those respondents in this study, given that the convenience sample was selected from a database of staff and students as an Australian university. In addition, administering the survey online is also a limitation because of the inability to control or monitor for environmental influences as well as technical difficulties for participants accessing, completing and returning surveys. Finally, findings are based on self-reported measures, and as such, the perceived significance of the speeding social issue could lead to problems of social desirability.

Despite these limitations, we believe the investigation should be extended across other social issues to see if the relationships hold. Also, despite the low explanatory power of the personality variables, the results do have implications for research because through the depiction of the personality construct 'propensity to comply with the speed limit', one moves closer to 
understanding individuals as a combination of traits. Moreover, this study highlights the importance of examining the direct and indirect effects of personality in relation to social issue involvement and behavior. Thus, a practical implication for social marketers is that some individuals are predisposed to respond positively to social issues and, therefore, place more importance on them. This, in turn, translates into engaging in the positive behavior promoted in the community - that is, complying with the speed limit.

Finding solutions to social issues necessitates social change and, thus, the advantage of the social marketing approach over other behavior intervention strategies such as education and law, is that social marketing focuses on understanding the target individual and the processes that drive that individual to behave in a particular manner (Rothschild, 1999). However, notwithstanding the influence of social marketing, ultimately the behavioral action, resides within the individual, and it is on that premise that this study is based. 


\section{References}

Andreasen, A. R. (1995). Marketing social change: Changing behavior to promote health, social development, and the environment. San Francisco: Jossey-Bass Publishers.

Andreasen, A. R. (2006). Social marketing in the $21^{\text {st }}$ century. Thousand Oaks, CA: Sage Publications, Inc.

Anderson Jr., W. T., \& Cunningham, W. H. (1972). The socially conscious consumer. Journal of Marketing, 36(July), 23-31.

Australian Transport Council. National road safety Strategy 2001-2010. Retrieved from http://www.atcouncil.gov.au/documents/atcnrss.aspx.

Bearden, W. O., Netemeyer, R. G., \& Teel, J. E. (1989). Measurement of consumer susceptibility to interpersonal influence. Journal of Consumer Research, 15, 473-481.

Benthin, A., Slovic, P., \& Severson, H. (1993). A psychometric study of adolescent risk perception. Journal of Adolescence, 16, 153-168.

Berkowitz, L., \& Lutterman, K. G. (1968). The traditional socially responsible personality. Public Opinion Quarterly, 32(Summer), 169-185.

Blackwell, R. D., Miniard, P. W., \& Engel, J. F. (2006). Consumer Behavior (10 ${ }^{\text {th }}$ ed.). Mason, OH: Thomson Higher Education.

Buss, A. H. (1989). Personality as traits. American Psychologist, 44(11), 1378-1388.

Chin, W. W., Marcolin, B. L., \& Newstead, P. R. (2003). A partial least squares latent variable modeling approach for measuring interaction effects: Results from a Monte Carlo simulation study and an electronic-mail emotion/adoption study. Information Systems Research, 14(2). 189-217.

Cooper, M. L., Wood, P. K., Orcutt, H. K., \& Albino, A. (2003). Personality and the 
predisposition to engage in risky or problem behaviors during adolescence. Journal of Personality and Social Psychology, 84(2), 390-410.

Dählback, O. (1990). Personality and risk-taking. Personality and Individual Differences, 11(12), $1235-1242$.

Department for Transport (2009). Chilling campaign warns drivers to kill their speed or 'Live With It'. Press release January 01, 2009. retrieved from http://www.dft.gov.uk/think/mediacentre/237066/2370701.

Ebreo, A., \& Vining, J. (2001). How similar are recycling and waste reduction? Future orientation and reasons for reducing waste as predictors of self-reported behavior. Environment and Behavior, 33(3), 424-448.

Falk, R.F. \& Miller, N.B. (1992). A primer for soft modeling. Akron, OH: University of Akron Press.

Fornell, C., \& Bookstein, F.L. (1982). Two structural equation models: LISREL and PLS applied to consumer exit-voice theory. Journal of Marketing Research, 12(September), 440-452.

Fornell, C., \& Cha, J. (1994). Partial least squares. In R. P. Bagozzi (Ed.), Advanced methods of marketing research (pp. 52-78). Cambridge, MA: Blackwell Publishers.

Gainer, B. (1993). An empirical investigation of the role of involvement with a gendered product. Psychology \& Marketing, 10(4), 265-283.

Green, C. L., \& Webb, D. J. (1997). Factors influencing monetary donations to charitable organizations. Journal of Nonprofit \& Public Sector Marketing, 5(3), 19-40.

Griffin, D., \& O’Cass, A. (2004). Exploring anti-smoking and anti-binge drinking issues in the context of generally accepted consumer theory. Journal of Nonprofit \& Public Sector Marketing, 12(2), 105-127. 
Gudergan, S. P., Ringle, C. M., Wende, S., \& Will, A. (2008). Confirmatory tetrad analysis in PLS path modeling. Journal of Business Research, 61, 1238-1249.

Hines, J. M., Hungerford, H. R., \& Tomera, A. N. (1986). Analysis and synthesis of research on responsible environmental behavior: A meta-analysis. The Journal of Environmental Education, 18(2), 1-8.

Horswill, M. S., \& McKenna, F. P. (1999). The effect of perceived control on risk taking. Journal of Applied Social Psychology, 29(2), 377-391.

Hume, M., \& Mort, G. S. (2008). Understanding the role of involvement in customer repurchase of the performing arts. Journal of Nonprofit \& Public Sector Marketing, 20(2),299-328.

Jackson, D., Hournay, L., \& Vidmar, N. (1972). A four-dimensional interpretation of risk taking. Journal of Personality, 40, 483-501.

James, H. W. (1957). Internal versus external locus of control of reinforcement as a basic variable in learning theory. Unpublished doctoral dissertation, Ohio State University, Ohio.

Jarvis, C. B., Mackenzie, S. B., \& Podsakoff, P. M. (2003). A critical review of construct indicators and measurement model misspecification in marketing and consumer research. Journal of Consumer Research, 30(2), 199-218.

Kotler, P., \& Lee, N. R. (2008). Social marketing: Influencing behaviors for good ( $3^{\text {rd }}$ ed.) Thousand Oaks, CA: Sage Publications.

Kropp, F., Lavack, A. M., Silvera, D. H., \& Gabler, J. R. (2004). Alcohol consumption among university students: A multi-country study of attitudes, values, identity and consumer influence. Journal of Nonprofit \& Public Sector Marketing, 12(2), 1-28. 
Lascu, D.N., Bearden, W.O., Rose, R.L. (1995). Norm extremity and interpersonal influences on consumer conformity, Journal of Business Research, 32(3), 201-212.

Laurent, G., \& Kapferer, J. N. (1985). Measuring consumer involvement profiles. Journal of Marketing Research, 22(February), 41-53.

Lindsay, J. J., \& Strathman. (1997). Predictors of recycling behavior: An application of a modified health belief model. Journal of Applied Social Psychology, 27(20), 1799-1823.

McGuire, W. J. (1968). Personality and susceptibility to social influence. In E. F. Borgatta \& W. W. Lambert (Eds.). Handbook of personality theory and research (pp. 1130-1187). Chicago: Rand McNally.

Mitchell, A. (1979). Involvement: a potentially important mediator of consumer behavior. In W. Wilkie (Ed.), Advances in Consumer Research, 6, 191-196. Ann Arbor: Association for Consumer Research.

Mittal, B. (1995). A comparative analysis of four scales of consumer involvement. Psychology and Marketing, 12(7), 663-682.

Moore, J. N., Raymond, M. A., Mittelstaedt, J. D., \& Tanner, J. F. (2002). Age and consumer socialization agent influences on adolescents’ sexual knowledge, attitudes and behavior: Implications for social marketing initiatives and public policy. Journal of Public Policy \& Marketing, 21(1), 37-52.

National Highway Traffic Safety Administration (2009). An analysis of speeding-related crashes: Definitions and effects of road environments (DOT-HS-811-090). U.S. Department of Transportation. Retrieved from http://www.nhtsa.dot.gov. 
O'Cass, A. (2000). An assessment of consumer product, purchase decision, advertising and consumption involvement in fashion clothing. Journal of Economic Psychology, 21,545576.

O’Cass, A. (2004). Electoral Choice: The effect of voter control and involvement on satisfaction and voting stability. Journal of Political Marketing, 3(1), 61-85.

Poulter, D. R., \& McKenna, F. P. (2007). Is speeding a “real” antisocial behavior?

A comparison with other antisocial behaviors. Accident Analysis and Prevention, 39, 384-389.

Ravichandran, T., \& Rai, A. (2000). Quality management in systems development: An organizational system perspective. MIS Quarterly, 24(3), 381-415.

Reinartz, W., Krafft, M., \& Hoyer, W. D. (2004). The customer relationship management process: Its measurement and impact on performance. Journal of Marketing Research, 41(3), 293-305.

Rose, R. L., Bearden, W. O., \& Teel, J. E. (1992). An attributional analysis of resistance to group pressure regarding illicit drug and alcohol consumption. Journal of Consumer Research, 19(June), 1-13.

Rothschild, M. (1999). Carrots, sticks, and promises: A conceptual framework for management of public health and social issues behaviors. Journal of Marketing, 63(4), 24-37.

Rothspan, S., \& Read, S. J. (1996). Present versus future time perspective and HIV risk among heterosexual students. Health Psychology, 15(2), 131-134.

Rotter, J. B. (1966). Generalized expectancies for internal v external control of reinforcement. Psychological Monographs, 80, 1-28. 
Schwebel, D. C., Severson, J., Ball, K. K., \& Rizzo, M. (2006). Individual difference factors in risky driving: The roles of anger/hostility, conscientiousness, and sensation-seeking. Accident Analysis and Prevention, 38, 801-810.

Schwepker Jr., C. H., \& Cornwell, T. B. (1991). An examination of ecologically concerned consumers and their intention to purchase ecologically packaged products. Journal of Public Policy \& Marketing, 10(2), 77-101.

Sitkin, S. B., \& Weingart, L. R. (1995). Determinants of risky decision-making behavior: A test of the mediating role of risk perceptions and propensity. Academy of Management Journal, 38(6), 1573-1592.

Smith, A. M. A. \& Rosenthal, D. A. (1995). Adolescents' perceptions of their risk environment. Journal of Adolescence, 18, 229-245.

Stanley, L. R., Lasonde, K. M., \& Weiss, J. (1996). The relationship between environmental issue involvement and environmentally-conscious behavior: An exploratory study. Advances in Consumer Research, 23, 183-188.

Stead, M., Tagg, S., MacKintosh, A. M., \& Eadie, D. (2005). Health Education Research, 20(1), 36-50.

Strathman, A., Gleicher, F., Boninger, D. S., \& Edwards, C. S. (1994). The consideration of future consequences: Weighing immediate and distant outcomes of behavior. Journal of Personality and Social Psychology, 66(4), 742-752.

Strickland, B. R. (1978). Internal-external expectancies and health-related behaviors. Journal of Consulting and Clinical Psychology, 46, 1192-1211.

Tenenhaus, M., Vinzi, V.E., Chatelin, Y.M. \& Lauro, C. (2005). PLS path modeling. Computational Statistics and Data Analysis 48(1), 159-205. 
Tucker, L. R., Dolich, I. J., \& Wilson, D. (1981). Profiling environmentally responsible consumer-citizens. Journal of the Academy of Marketing Science, 9(4), 454-478.

Ulaga, W., \& Eggert, A. (2006). Relationship value and relationship quality: Broadening the nomological network of business-to-business relationships. European Journal of Marketing, 40(3/4), 311-327.

Ulleberg, P., \& Rundmo, T. (2003). Personality, attitudes and risk perception as predictors of risky driving behavior among young drivers. Safety Science, 41, 427-443.

Wallston, K. A. \& Wallston, B. S. (1981). Health locus of control scales. In Research with the locus of control constructs, Vol. 1. (pp. 189-243). New York: Academic Press.

Webster Jr., F. E. (1975). Determining the characteristics of the socially conscious consumer. Journal of Consumer Research, 2(December), 188-197.

Wetzels, M. Odekerken-Schröder, G., \& van Oppen, C. (2009). Using PLS path modeling for assessing hierarchical construct models: Guidelines and empirical illustration. MIS Quarterly, 33(1), 177-195.

Zimbardo, P. G, Keough, K. A., \& Boyd, J. N. (1997). Present time perspective as a predictor of risky driving. Personality and Individual Differences, 23, 1007-1023. 


\section{Table 1}

Outer Model Results for Constructs

Components and Manifest Variables

Loadings $^{\mathrm{a}}$

Risk Aversion (Reliability: .89, AVE .67)

I can be rather incautious and take risks. ${ }^{\circledR}$

In general, I am rather adventurous and like to take chances. ${ }^{\circledR} \quad 88$

Generally, I think I am rather bold and fearless in my actions. ${ }^{\circledR} \quad .78$

I think I am often less cautious than other people in general. ${ }^{\circledR} \quad .77$

Locus of Control (Reliability .87, AVE .46)

Many times I feel that we might as well make our decisions by flipping a coin. ${ }^{\circledR}$

Getting a good job seems to be largely a matter of being lucky enough to be in the right place at right time. ${ }^{\circledR}$

It isn't wise to plan too far ahead because many things turn out to be a matter of good or bad fortune anyway. $\circledR$

When things are going well for me I consider it due to a run of good luck. ${ }^{\circledR}$

I have usually found that what is going to happen will happen, regardless of my actions. ${ }^{\circledR} \quad .74$

Success is mostly a matter of getting good breaks. ${ }^{\circledR}$

There's not much use in worrying about things; what will be will be. ${ }^{\circledR} \quad .63$

I think life is mostly a gamble. ${ }^{\circledR} \quad 72$

Many time I feel that I have little influence over the things that happen to me.®

Susceptibility to Normative Influence (Reliability .94, AVE .66)

I rarely purchase the latest fashion styles unless my friends approve of them. $\quad .63$

It is important that others like the products and brands I buy. $\quad .84$

When buying products, I generally purchase those brands that I think others will approve of. $\quad .88$

If other people can see me using a product, I often purchase the brand they expect me to buy. $\quad .87$

I like to know what brands and products make good impressions on others. $\quad .79$

I achieve a sense of belonging by purchasing the same products and brands that others purchase. $\quad .85$

If I want to be like someone, I often try to buy the same brands that they buy. $\quad .79$

I often identify with other people by purchasing the same products and brands they purchase. $\quad .81$

Social Responsibility (Reliability .81, AVE .52)

I think we should all try to enhance the welfare of others through our actions. $\quad .73$

I gauge my behavior by its impact on others and society. $\quad .60$

Every person should volunteer some of their time for the good of their community or society. $\quad .73$

We all have a responsibility to look out for others in society. $\quad .82$

Involvement (Reliability .95, AVE .80)

This social issue [speeding] is important to me 93

This social issue[speeding] means a lot $\quad .93$

$\begin{array}{ll}\text { This social issue[speeding] matters } & .94\end{array}$

This social issue[speeding] is significant $\quad .90$

This social issue[speeding] is of no concern ${ }^{\circledR} \quad .75$

${ }^{\text {a }}$ Bootstrap critical ratios are not shown but they were all significant at $P<.05$.

Table 2 
Formative Construct Weights for Propensity to Comply with the Speed Limit

\begin{tabular}{lcc}
\hline Construct & Weights & Critical Ratio \\
\hline Risk Aversion & .630 & 3.97 \\
Locus of Control & -.256 & $\mathrm{~ns}$ \\
Consideration of Future Consequences & .637 & 2.83 \\
Susceptibility to Normative Influence & -.265 & 1.82 \\
\hline
\end{tabular}

Table 3

\section{Hypotheses Results}

\begin{tabular}{|c|c|c|c|c|c|c|}
\hline Predicted Variables & Predictor Variables & Hyp.s & Path & $\begin{array}{l}\text { Variance }^{\text {a }} \text { due to } \\
\text { path }\end{array}$ & $R^{2}$ & $\begin{array}{l}\text { Critical } \\
\text { Ratio }^{\text {b }}\end{array}$ \\
\hline \multirow[t]{2}{*}{$\begin{array}{l}\text { Speed limit compliance } \\
\text { behavior }\end{array}$} & $\begin{array}{l}\text { Propensity to comply with } \\
\text { speed limit }\end{array}$ & H1 & .220 & .066 & & 4.23 \\
\hline & $\begin{array}{l}\text { Involvement in the speeding } \\
\text { social issue }\end{array}$ & H5 & .316 & .118 & .18 & 7.80 \\
\hline Social Responsibility & $\begin{array}{l}\text { Propensity to comply with } \\
\text { speed limit }\end{array}$ & $\mathrm{H} 2$ & .105 & .011 & .01 & 1.50 \\
\hline \multirow[t]{2}{*}{$\begin{array}{l}\text { Involvement in the speeding } \\
\text { social issue }\end{array}$} & $\begin{array}{l}\text { Propensity to comply with } \\
\text { speed limit }\end{array}$ & H3 & .221 & .056 & & 4.63 \\
\hline & Social Responsibility & $\mathrm{H} 4$ & .314 & .106 & .16 & 8.15 \\
\hline $\operatorname{AVA}^{\mathrm{c}}$ & & & & & .12 & \\
\hline
\end{tabular}

\footnotetext{
${ }^{\mathrm{a}}$ These are only interpreted if the $R^{2}$ is greater than 0.10

${ }^{\mathrm{b}}$ Bootstrap estimate divided by bootstrap standard error

c Average Variance Accounted for
} 


\section{Figure 1}

Multi-trait Drivers of Speed Limit Compliance Behavior

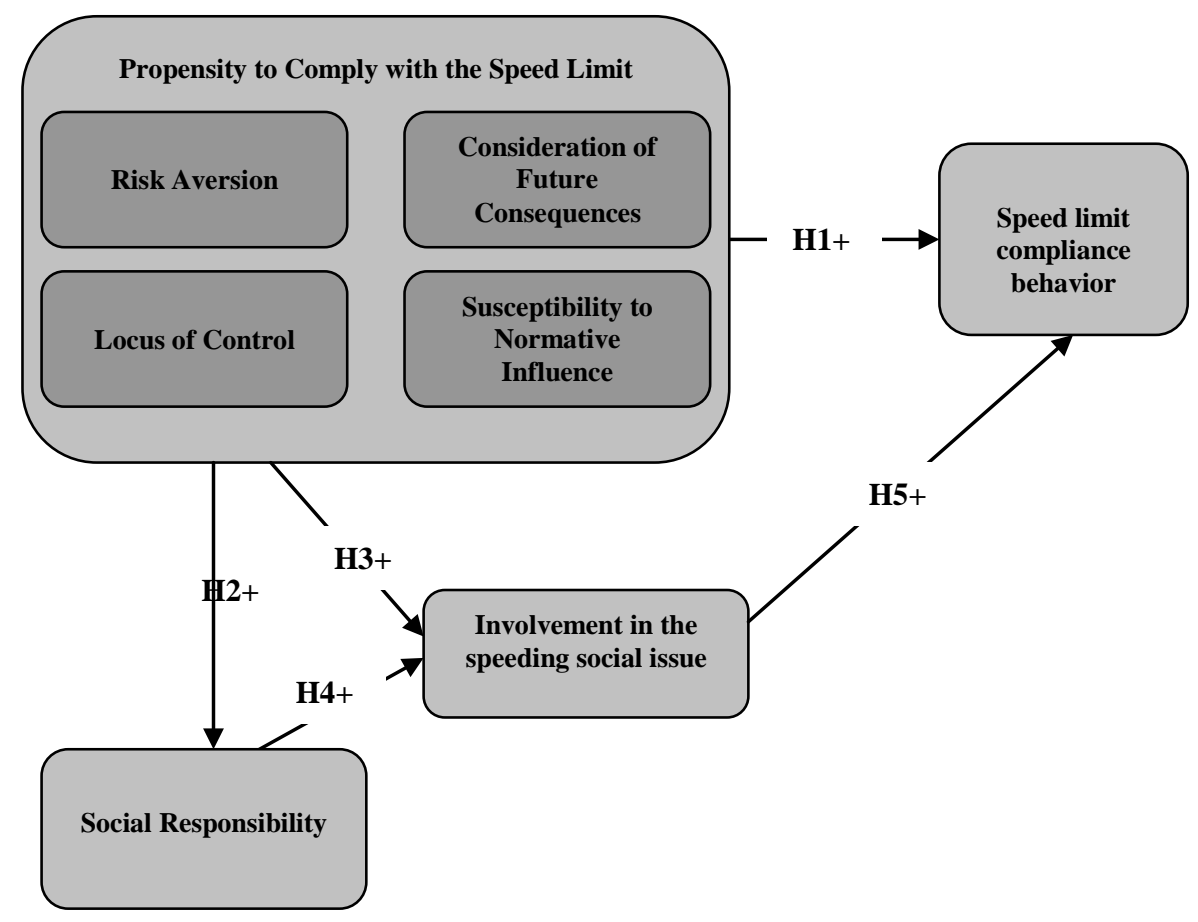

